\title{
Formação em museologia: círculos e outras geometrias
}

\begin{abstract}
Alice Semedo ${ }^{1}$
RESUMO: Este artigo explora algumas inquietações e valores que fazem parte da reflexão sobre os processos de coabitação flexível no âmbito da formação em museologia, produzindo teorias mais matizadas, práticas mais refletidas e, porventura, museus menos ilusórios. Introduzse, ainda, uma reflexão sobre a própria natureza do conhecimento em museologia. $\bigcirc$ conhecimento é teorizado como um quase objeto, um híbrido entre sujeito, humano e nãohumanos, desafiando a separação entre sujeito e objeto, entre natureza e sociedade, entre teoria e prática. A museologia é aqui apresentada enquanto objeto quase de investigação / formação, como espaço de questionamento não delimitador mas de contornos cada vez mais de fronteira, impermanente e pertencendo ao que se vem denominando de Modo 2/3 de produção de conhecimento.

PALAVRAS-CHAVE: Museologia. Formação. Espaços-quase.
\end{abstract}

ABSTRACT: This article explores some of the concerns and values that are part of the discussion about processes of flexible cohabitation in training in museology producing more nuanced theories, more reflective practices, and possibly less illusory museums. It also introduces a discussion on the very nature of knowledge in museology. Knowledge is theorized as a quasiobject, a hybrid between subject, human and nonhuman, challenging the separation between subject and object, between nature and society, between theory and practice. Museology is presented here as a quasi-object of research / training as a space for questioning not delimiter but which increasingly adopts border contours, impermanent and belonging to what has been denominated Mode 2/3 of knowledge production.

KEYWORDS: Museology. Training. Quasi-spaces.

Numa destas manhãs mais madraças entre cafés e jornais, conheci Elif Shafak, que eloquentemente falava do poder dos círculos, percorrendo lugares e geometrias que a vida vai tecendo e deixando-me aqui e ali uma ou outra estória
1. Professora Auxiliar do Departamento de Ciências e Técnicas do Património da Faculdade de Letras da Universidade do Porto. Licenciada em História, variante Arqueologia, pela Faculdade de Letras da Universidade de Coimbra. Mestre e Doutora em Estudos de Museus pela Universidade de Leicester (Reino Unido). Directora do $2^{\circ}$ Ciclo de Museologia (FLUP), onde lecciona disciplinas de diferentes áreas. E-mail: <semedo.alice@gmail. com>. 
2. Ver: Elif Shakaf (2010).

3. Cf. Eilean Hooper-Greenhill (1992, p.3)

4. Como afirmou Scott Lash durante a sua intervenção no Porto, no Colóquio $\mathrm{Mu}$ seus, Discursos e Representações, em 2004 que a todos nos toca². A Elif é uma excelente contadora de estórias. A estória despretensiosa sobre o poder dos círculos tocou-me particularmente. Da lição da avó materna e das suas mezinhas contra a acne e outras barbaridades juvenis - que sabiamente a acautelava em relação ao poder dos círculos tocou-me particularmente. Da lição da avó materna e das suas mezinhas contra a acne e outras barbaridades juvenis - que sabiamente a acautelava em relação ao poder dos círculos aprendeu, entre muitas outras coisas, uma lição preciosa: se quisermos apagar ou destruir alguma coisa nesta vida, seja uma mancha ou a alma humana, tudo o que precisamos é de a rodear com altos muros: tudo seca no seu interior! Ora todos vivemos nalgum tipo de círculo social e cultural - dizia-me acenando - se não tivermos qualquer relação que seja com os mundos para além daquele que tomamos por garantido e certo... corremos o risco de secar no seu interior! A nossa imaginação estreita-se. Os nossos corações diminuem e a nossa qualidade humana definha se ficarmos demasiado tempo fechados nos nossos casulos culturais. Se todas as pessoas no nosso círculo interior se assemelham a nós... se todos os nossos amigos, vizinhos, colegas, família se apresentam como nós... bem... isso significa que estamos rodeados pela nossa imagem ao espelho! Na tradição árabe, confidenciou ainda Elif, os espelhos são amiúde cobertos por veludo ou voltam-se ao contrário pois não é saudável para um ser humano despender demasiado tempo a olhar para a sua própria imagem refletida.

A sua conversa alongou-se por outros temas mas é esta sua metáfora do poder dos círculos que aqui tomarei emprestada, muito livremente, para pensar sobre a formação em museologia. É que me ocorreu que - embora não seja essa de todo a minha intenção primeira -, enquanto docente de museologia - e ultimamente directora de um Curso -, ao falar de formação me vejo amiúde a desenhar fronteiras que inscrevem linhas identitárias balizadas por círculos mais ou menos fixos. Assim, e embora falando sempre do ponto de vista da minha experiência enquanto docente do Curso de Museologia da Universidade do Porto, aproveitarei esta oportunidade para me aventurar por alguns terrenos, porventura mais movediços, mas que a mim me têm desde sempre interessado e que têm feito parte dos meus percursos sobre formação e aprendizagens em museologia. Ou seja, por alguns desses territórios que medeiam a teoria e a prática. Terei, porém, que voltar à pré-história deste Curso e contextualizar o seu surgimento.

Eilean Hooper-Greenhill escrevia no início dos anos 90 do século passado que o museu, enquanto objeto de estudo, continuava praticamente invisível e que para a grande maioria dos investigadores se mantinha como que coberto por um "manto de silêncio crítico" ${ }^{3}$. Todavia a leitura rápida de qualquer listagem de uma editora internacional, como por exemplo a Routledge, demonstra que, decorridos vinte anos, os museus se tornaram sexys ${ }^{4}$ e que um grupo cada vez maior de investigadores de diversos campos investiga e escreve sobre este artefato social. O Curso de Museologia da Universidade do Porto iniciou a sua viagem, justamente, na altura em que se assistia a este crescimento editorial sem precedentes sobre museus e património. Livros sobre os mais diversos assuntos, antologias, actas 
de conferências acerca de museus, proliferam desde então no contexto do fenómeno museológico, como the chamou Gordon Fyfe 5 . Fenómeno museológico que podemos relacionar com os processos que têm sido caracterizados como pósindustriais, pós-capitalistas, modernidade tardia ou pós-modernos a que normalmente se aliam, entre outras, motivações e ansiedades relacionadas com a amnésia social; procura de autenticidade e antídotos em relação à sociedade de consumo; tentativas de lidar com a fragmentação da identidade e individualização; desejos de aprendizagem ao longo da vida e de aprendizagem vivencial. Contudo, este era e tem sido um momento de particular fragmentação e profundo questionamento deste mundob.

Quando iniciei o meu percurso de docência no início dos anos 1990, primeiro em Coimbra e depois no Porto, as próprias universidades encontravam-se em pleno processo de transformação, abrindo-se a mais amplos setores sociais, democratizando-se, feminizando-se, buscando a internacionalização e, num contexto de mudança de paradigma tecnológico e de um novo sistema de regulação, procuravam, igualmente, adaptar-se às demandas e inovações em curso no mercado de trabalho e na sociedade, assumindo um novo "vocacionalismo"7. Embora a partir de meados da década de 1990 alguns estudos apontem a presença de valores pós-materialistas na sociedade portuguesa ${ }^{8}$, em linhas gerais, as décadas de 1980 e 1990 foram fortemente marcadas por valores economicistas que acentuavam o apelo à modernização e a necessidade de uma forte ligação entre a Universidade e o mundo do trabalho. Além disso, a influência das redes de globalização nos processos de construção das políticas educativas, culturais, patrimoniais e museológicas e outras, quer no estabelecimento das agendas políticas, quer na conceptualização e implementação das orientações e medidas políticas e programas educacionais, não pode ser desmerecida e deve ser tida em conta na intenção destas estratégias ${ }^{9}$. Ora será precisamente no âmbito desta mudança intelectual e ambiente político que em termos universitários, a formação em museologia começava, no início da década de 1990, em Portugal, a dar também os primeiros passos ${ }^{10}$.

Será pois neste contexto que negociarei - fará por agora vinte anos - a minha entrada neste círculo de cultura com um master de uma universidade anglosaxónica e uns poucos de estágios em alguns museus considerados de prestígio, chegando ao mundo dos museus enquanto estrangeira. As estrangeirices foram, no início, incompreendidas neste mundo que, apesar de alguma abertura, ainda mantinha círculos de hostilidade, suspeitando-se de conceitos, palavras novas e de interpretações teóricas que eram rejeitadas em favor de conhecimentos empíricos e acríticos. Embora não se encontrassem completamente alheios às questões teóricas - aliás diria que, na generalidade, o mesmo se vai passando hoje em dia - a maior parte dos profissionais de museus encontrava-se profundamente enraizada em políticas de interesse e pouco seduzida ou mesmo disponível para responder às questões estruturais discutidas na investigação, a interpretações mais teóricas e críticas. Por outro lado, da parte das universidades, a investigação sobre museus
5. Cf. Gordon Fyfe (2006, p. 40).

6. Diferentes estudos em Portugal, França, Estados Unidos e Reino Unido referem, por exemplo, tensões e crises de identidade no modelo profissional dos conservadores (ver, por exemplo, Sylvie Octobre (2001); Alice Semedo (2003) e Vera Zolberg (1986)). Com base no modelo tradicional de museus, a profissão de conservador surge dividida entre a lealdade para com as funções em torno do estudo e preservação das coleções e as transformações em relação à sua missão e valores públicos de acessibilidade e democracia. Fragmentação que evoca a revolução conceptual de que vêm falando vários autores; ver, por exemplo, Hilde Hein (2000).

7. Cf. Alan Stoleroff et al. (1990).

8. Ver Maria Eduarda Gonçalves (2001); para essas questões e dicotomias, ver ainda, por exemplo, Fernando Machado e Firmino Costa (1998).

9. Cf. Madalena Mendes (2007).

10. O Curso de Especialização em Museologia será criado na Faculdade de Letras da Universidade do Porto em 1992 por uma Comissão formada por um grupo de Professores de carreira que tentou, por um lado e após várias consultas com o meio profissional, adequar o Curso às diretrizes do International Council of Museums e, por outro, encontrar docentes que embora não fizessem parte do quadro da Faculdade, tivessem competências nas diferentes áreas, então novas para esta Faculdade, tais como: gestão de coleções museológicas, conservação preventiva, arquitectura de museus, novas 
tecnologias aplicadas a museus, etc. Com um apoio indiscutível e constante desta Comissão, o grupo de docentes com diferentes perfis académicos e profissionais (por exemplo, Arquitectura, Biologia, Design, Arqueologia, Estudos de Museus, Conservação Preventiva; alguns com grande experiência e ligação ao mundo profissional) assume grande autonomia no desenvolvimento de programas e atividades. Logo no início dos anos 1990 é, igualmente, criado na Faculdade de Letras, o Departamento de Ciências e Técnicas do Património que integrará quatro Secçõesh: Arqueologia, História de Arte, Ciência de Informação e Museologia. Naturalmente, o Curso tem sido alterado ao longo destes últimos quinze anos e se em 1992 se criou o Curso de Especialização e a área de Doutoramento em Museologia, avançou-se, depois, para a fase de Curso Integrado (Mestrado e Doutoramento) e, hoje em dia, a Faculdade de Letras da Universidade do Porto oferece um Curso de $2^{\circ}$ e $3^{\circ}$ Ciclo em Museologia (Mestrado e Doutoramento) sendo, aliás, este último Ciclo já uma parceria com a Faculdade de Belas-Artes que integra, ainda, Professores das Faculdades de Arquitectura, Engenharia e Medicina. O Curso encetará as atividades letivas em 2004 num contexto de profunda renovação do tecido museológico português, três anos apenas depois da criação do Instituto Português dos Museus e numa altura em que o próprio setor se procurava autonomizar, procurando apresentar uma política coerente e coordenada para esta área que cada dia ganhava mais espaço de discussão nos media. Consultar outra informação sobre o Plano do Curso em < http://sigarra. up.pt/flup/cursos_geral. FormView?P_CUR_SIGLA= MMUS>. e museologia tem mantido em muitos casos este distanciamento que se reflete quer no enfoque, quer nas práticas de ensino e investigação que concebem. Investigação que é amiúde apontada como sendo excessivamente teorizada e que demonstra uma frágil relação com o mundo real. Lynne Teather observa que os profissionais praticantes ${ }^{11}$ crêem que os textos teóricos estão de tal forma sobrecarregados de vocabulário especializado e enraizados numa determinada disciplina teórica que não têm qualquer relação com a sua vida de trabalho ${ }^{12}$.

Por outro lado, não há dúvida de que a construção teórica é importante para o desenvolvimento de qualquer profissão, pois é a fundamentação teórica de conhecimentos e competências que permite um certo grau de abstração na descrição e aplicação do trabalho, promovendo a versatilidade e adaptabilidade às mudanças ao longo do tempo e às necessidades da sociedade ${ }^{13}$. Com esta categorização em mente veremos, aliás, que a teoria e a prática, quando compreendidas enquanto formas separadas de perceção, se assumiram como formas distintas de pensar os museus.

Danielle Rice diz-nos que esta clivagem entre teoria e prática produz, afinal, museus ilusórios, ou uma série de museus ilusórios, e que ao desenvolvermos investigação e formação em museologia - deste tipo, ou seja, separada da prática - alimentamos também, afinal, a ilusão ${ }^{14}$. Como Rice, interesso-me sobretudo por estes espaços de encontro - possivelmente mais performativos e relevantes - que me parecem mais frutuosos e que podem ser encontrados entre a teoria e a experiência, resultando, em teorias mais matizadas e em práticas mais refletidas e que, porventura, ultrapassam os constrangimentos dos círculos de que comecei por falar. Espaços de encontro e coabitação flexível, portanto, e que no âmbito das práticas de docência / formação / investigação tenho cada vez mais procurado materializar e que pouco se conformam com as restrições que as fronteiras de que aqui venho falando tendem a desenhar. Há ainda uma outra observação desta autora $^{15}$, que aqui me parece interessante ter em conta, que adverte as universidades e os seus cursos de museologia em relação aos processos de endoutrinação crítica, que inadvertidamente representam os museus como instituições desiguais de poder, monolíticas e exclusivas a que a influência dos estudos de Hooper-Greenhill e de Duncan, por exemplo, não será alheia ${ }^{16}$. Os processos culturais descritos por estas análises são, porém, bem mais complexos e a versão deste "lado político, diabólico dos museus" é necessariamente incompleta e difícil de conciliar com as actuais missões e práticas museológicas. Expressivamente, nesses estudos e na museologia, em geral, a agência é explorada, sobretudo, analiticamente e empiricamente, em termos de força produtiva dos museus e não dos seus visitantes. Todavia, esta tendência em termos de abordagem de investigação tem sido objeto de crítica recente ${ }^{17} \mathrm{e}$, a verdade, é que outras abordagens, ao explorarem as construções dos visitantes em relação ao objeto museu, das interações serendipidiosas, das agendas e narrativas que cada um traz / leva para / deste espaço - subvertendo tantas vezes completamente os seus propósitos - encontraram um mundo complexo e extremamente rico de apropriações ${ }^{18}$. 
Danielle Rice adapta o conceito de horizonte de eventos, utilizado no meio artístico, como forma de ultrapassar a tendência de representação do museu (e da museologia) enquanto objeto estático, propondo uma análise que inclua os cruzamentos entre o quotidiano, quer como representado pelas experiências dos visitantes e profissionais, quer pela bibliografia mais teórica ${ }^{19}$. Desta forma, o horizonte de eventos dos museus incluiria as muitas vozes que os museus se propõem representar antes que a sua multiplicidade se transforme em apenas confusão e ruído. Espaços de interseção onde a teoria e a prática se encontram antes de desabarem num buraco negro de incompreensão - como esta autora mesmo enfatiza -, e que constituiriam, então, o horizonte de eventos para a museologia.

Um outro aspeto que é, frequentemente, apontado neste contexto, referese quer à transformação dos museus, quer ao ensino da museologia em termos de centralidade vocacional. Atualmente os museus aspiram a ser lugares de emaravilhamento, de encontro e de reflexão, de criatividade e de aprendizagem deixando, assim, de se desenharem como meros repositórios de objetos. Se tradicionalmente os currículos de museologia se concentravam no modelo objeto, instituição, equipa e público, centrando-se na abordagem das funções museológicas e no estudo das coleções, pede-se-lhes agora que se pensem mais em ideias / pessoas / missões-base, acompanhando a transformação do $\operatorname{campo}^{20} \mathrm{e}$ valorizando, sobretudo, o valor educacional dos museus. Esta mudança tem conduzindo a um distanciamento da centralidade dos objetos em direção a uma ênfase na promoção da experiência, levando, por vezes, a uma desvalorização das coleções do museu como fonte de verdadeiro significado e valor e a uma subordinação em torno da experiência museológica ${ }^{21}$; ênfase que revela novos horizontes éticos, epistemológicos e estéticos. Todavia, é também evidente no mundo dos museus um retorno ao mundo das coleções e do papel central da investigação das coleções, produzindo materializações museológicas que, de qualquer forma, não se centram apenas na experiência cognitiva mas favorecem, identicamente, a experiência vivencial e sensível dos visitantes e dos próprios curadores / investigadores / connaisseurs falando, abertamente, sobre as coleções e discutindo-as; abrindo espaços de visibilidade no discurso, por exemplo, aos processos situados de investigação e de colecionar enquanto experiência e história que, com o apoio das novas tecnologias e no âmbito do que pode tem sido apelidado de memory turn ${ }^{22}$ e de visual turn ${ }^{23}$ - como já referi - tem ganho um espaço crítico importante não só junto dos profissionais (museus e currículos de ensino) mas também dos próprios públicos.

No modelo de museu participativo descrito por Nina Simon ${ }^{24}$, os espaços tornam-se fluídos, conversações em contínuo estado beta; o museu, plataforma distribuída e flexível; e a coleção, recurso que promove uma arquitetura de participação, interações colaborativas /algumas planeadas outras, talvez, mais espontâneas), que acontecem através de conexões múltiplas e alargadas de ideias, de pessoas e objetos, ultrapassando, frequentemente, fronteiras demasiado
11. Cf. Sylvie Octobre (2001).

12. Cf. Lynne Teather (1991, p. 404).

13. Cf. Lynne Teather, Peter van Mensch e Sara Faulkner-Fayle (1999).

14. Cf. Danielle Rice (2003, p.78).

15. Idem, p. 7-78.

16. Cf. Eilean Hooper-Greenhill (1992) e Carol Duncan (1995).

17. Ver, por exemplo, Lianne McTavish (2005) e Colin Trodd (2003).

18. Ver, por exemplo, John Falk (2009), Nicholas Mirzoeff (1999) ou, ainda, Mihalyi Csikszentmihalyi e Rick Robinson (1990).

19. Cf. Danielle Rice (2003, p. 79).

20. Cf. Wendy Duff, Joan Cherry e Rebecka Sheffield (2010).

21. Cf. Hilde Hein ( 2000, p. VIII).

22. Cf. Pierre Nora (1989).

23. Cf. Nicholas Mirzoeff (1999).

24. Cf. Nina Simon (2007). 
25. Cf. Stephen Greenberg (2005, p. 226-237).

26. Cf. Anthony Shelton (2009).

27. Ver, por exemplo, Patrick Jenlink e Karen Jenlink (2009).

28. Cf. John Dewey (1916).

29. Cf. Jim McGuigan (2005; 2007).

30. Cf. John Dewey (1916, p. 97). disciplinadas e ambicionando a incorporar as interações havidas entre os visitantes nas próprias experiências museológicas. Assumindo, enfim, contornos vitais ${ }^{25}$ nos quais as fronteiras entre artefatos e públicos se pensam em termos de experiência transformadora, e não tanto em termos de objeto estático.

\section{Espaços-quase}

O ambiente de trabalho deste Curso proporcionou - desde sempre - um crescimento com alguma autonomia da museologia, enquanto área de investigação interdisciplinar e área de trabalho profissionalizante. Crescimento em permanente diálogo com outras áreas do saber que fogem às fronteiras do Departamento a que pertencemos. Esta autonomia permitiu que os diferentes docentes pensassem programas, políticas e desenvolvessem mais livremente estratégias de trabalho com os alunos e com os diferentes parceiros no terreno, explorando e, particularmente, construindo territórios numa lógica de relações de confiança e serviço. Nessa construção mais livre, mas eventualmente mais próxima, do objeto museológico, desde cedo os profissionais-praticantes assumiram o papel de intervenientes ativos na construção do objeto de formação, não só fazendo intervenções em ambiente de sala de aula mas, igualmente, co-orientando trabalhos académicos e estágios, produzindo, desta forma, eventuais práticas curatoriais e de ensino, de fertilização cruzada ${ }^{26}$, objetos mais produtivos e críticos.

É pensando em torno do conceito de museu vital, e de acordo com os estudos contemporâneos ${ }^{27}$, que também imagino a formação no âmbito da museologia como sendo profundamente reflexiva, crítica; promovendo competências de trabalho em equipa e profissionais claramente habituados a utilizar a teoria para melhorar as suas práticas. Imagino, particularmente, uma educação que apoie a democracia cultural que, como argumentava Dewey ${ }^{28}$, se refere à promoção de espaços de ação comunicativa, de partilha das vozes pessoais nos espaços intermédios e de construção do espaço cultural público ${ }^{29}$, onde os diferentes atores participem ativamente na identificação de temas e questões, partilhando concetualizações, construções e metodologias. Esta visão - necessariamente relaciona-se, então, com a visão sobre o próprio objeto museológico. Dewey argumentava que pensar a educação enquanto processo social e função, não fazia sentido concludente se não definíssemos o tipo de sociedade que temos em mente ${ }^{30}$. Ora quando definimos a sociedade - e no caso particular que aqui nos traz, quando definimos o museu - enquanto democrático, conversação e recurso, então há que desenhar um plano de formação que incorpore esses valores, numa ética reflexiva, colaborativa, experimental que, ao abranger outros atores, inclua, eventualmente, diferentes visões e definições; apoie os alunos na utilização das suas próprias vozes, envolvendo-os na análise crítica, na ação e na construção de relações significantes. Por outro lado, o desenho destas fronteiras e destes círculos - nomeadamente a separação entre os mundos da teoria e da prática - também deixa, aqui, de fazer sentido. Mas a verdade é que a teoria e a prática traçam 
frequentemente fronteiras que fazem com que profissionais e académicos representem estes mundos enquanto separados.

31. Cf. Alice Semedo e Inês Ferreira (2011)

Desde que me acerquei a este mundo que me tenho deparado inúmeras vezes com este tipo de aforismos e vejo a relevância da teoria ser constantemente questionada no mundo dos museus: a teoria é uma coisa mas a prática é outra completamente diferente; ou, a teoria é algo que não funciona na prática. A noção de que a teoria se encontra separada do mundo da prática é, na verdade, persistente nos domínios profissionais, resultando num empirismo ingénuo e em comportamentos rotineiros. Coordeno neste momento um projeto de investigação ação colaborativa que se encontra em pleno processo de desenvolvimento / construção e implementação e que, muito resumidamente, pretende criar espaços colaborativos de construção entre a universidade e os museus da cidade (neste caso os profissionais de serviços educativos) para - numa eventual segunda fase do projeto - envolver outros parceiros do terreno nestas construções sobre a natureza do trabalho museológico e o objeto museu, nomeadamente, diferentes comunidades $^{31}$. $O$ trabalho decorre mais ou menos ao longo de um ano e entre outras ações para além de se pedir aos participantes que utilizem um diário como um instrumento essencial de reflexão, organizaram-se uma série de pequenos workshops mensais de trabalho.

Contudo, alguns dos comentários registados, levam-me a pensar que o meu papel enquanto investigadora e participante da ação não parece claro para todos os envolvidos. Para a maior parte (muitos foram alunos do Curso), o meu envolvimento nas discussões e diferentes actividades não thes será estranho mas, para outros, é difícil conceber este projeto - que é ação - enquanto investigação. A surpresa perante o interesse e atitude da Universidade, de uma das excelentes pessoas que orientou o último workshop e que tem larga experiência prática no campo do trabalho com museus, demonstra bem as representações que circulam no campo. Parecia-the estranho... Enquanto caminhávamos à hora de almoço pelos jardins do museu, perguntava-me como me tinha lembrado de um projeto assim... um projeto, enfim... prático, de ação... A uma pessoa habituada há tanto a trabalhar na e com a prática parecia-the quase inconcebível que partisse da Universidade um projeto deste tipo.

A teoria é habitualmente associada a modelos, princípios organizadores e metodologias que, como tal, muitos compreendem como sendo fixa e, logo, limitadora. Ao invés, a prática é apreendida enquanto ação, como sendo, relacionando-se com "coisas, atos reais" e com o que "realmente importa" e, portanto, muito diferente e separada da teoria. A materialidade e o significado separam-se e a teoria posiciona-se de forma a constituir-se enquanto obstáculo para as realizações no mundo real, no mundo da prática (as teorias só complicam tudo). Um dos objetivos deste projeto de investigação e dos programas do Curso tem sido superar este binário, que obstrui relações mais autênticas e profundas entre o mundo dos profissionais praticantes, as universidades e as comunidades. Um dos maiores impedimentos para o desenvolvimento deste tipo de investigação e aprendizagem 
32. Esta é uma situação que não afecta só as Universidades Portuguesas como o estudo, por exemplo, de Frank van Rijnsoever e K. Laurens Hessels (2011).

33. Sobretudo das disciplinas do $1^{\circ}$ ano do Curso de $2^{\circ}$ Ciclo em Museologia: Estudos e Gestão de Coleções; Políticas e Práticas de Comunicação em Museus.

34. A disciplina de Estudos e Gestão de Coleções, por exemplo, surge no primeiro semestre do primeiro ano do $2^{\circ}$ ciclo do Curso Museologia e pretende proporcionar aos alunos conhecimentos sobre a natureza das coleções museológicas, explorando algumas das questões contemporâneas dos estudos de cultura material, introduzindo princípios, estratégias e recursos de investigação das coleções, nomeadamente no que diz respeito à constituição das coleções; num segundo momento, a disciplina endereça tópicos de carácter mais prático e que se relacionam com a gestão das coleções e com o desenvolvimento de políticas coerentes e sustentáveis neste campo de acção. Considera-se que esta disciplina garante aos alunos oportunidades para desenvolverem competências essenciais para iniciarem o seu percurso profissional em museus: conhecimentos de deontologia profissional e a capacidade de investigar e concetualizar questões relacionadas com a natureza das coleções museológicas e com a sua gestão. Assim, o projeto constitui-se como uma pesquisa multidimensional incentivando os alunos a desenvolver diversas competências, incluindo, pensamento crítico e criativo, inventário e documentação das coleções, recolha e análise de dados (envolvendo técnicas quantitativas e qualitativas, nomeadamente visuais), escrita $\mathrm{e}$ diferentes formas de comu- penso que reside, porém, na própria universidade que tende a valorizar abordagens mais tradicionais. A vida académica divide as nossas actividades padrão, nomeadamente a investigação, ensino / orientação, atribuindo-the recompensas materiais e estatutos diferentes (no nosso currículo e avaliação), enfatizando a abstração, segmentação, quantidade e hierarquização, frequentemente à custa do apoio e relação com o mundo real e trabalho prático com os alunos. Da parte da universidade e em termos reais, existe também uma desvalorização em relação a este tipo de trabalho prático e trans ou interdisciplinar ${ }^{32}$.

No âmbito dos programas das disciplinas que leciono ${ }^{33}$ procuro ultrapassar esta clivagem que persistentemente encontro no campo, entre o modo de pensar (ensino) teórico e prático. Assim, e tanto quanto possível, as diferentes cadeiras do Curso tentam relacionar os tópicos de trabalho entre si, centrando os alunos num local de trabalho / museu / coleção. Aos alunos que não se encontram a trabalhar em meio museológico proporciona-se-lhes, desde o início das actividades letivas, a participação em trabalhos práticos, numa tentativa de integração da teoria e a prática, utilizando as concetualizações teóricas enquanto orientações do seu conhecimento prático e testando, ainda, as limitações e possibilidades da teoria na prática $^{34}$. Os alunos participam em situações práticas, atuando directamente no mundo do trabalho, confrontando-se com problemas reais e refletindo sobre as consequências (também éticas) das suas ações. Pede-se ao estudante que desenvolva competências de liderança e que pense em termos sintetizadores, que integre conhecimentos de vária ordem e, por isso mesmo, que trabalhe em equipas multidisciplinares; que estabeleça relações entre os contextos e as estruturas explanatórias mas que tenha em conta, igualmente, questões de identidade pessoal, valores e visões; que responda, enfim, às complexidades do mundo real. $\bigcirc$ estágio ou desenvolvimento de um projeto têm sido oportunidades reveladoras para colocar a teoria em ação, oferecendo, em alguns casos, oportunidade de emprego e empowerment, contribuindo, por outro lado, para a introdução e construção de concetualizações e práticas com os diferentes parceiros envolvidos.

Apesar das dificuldades, do planeamento e do esforço necessário requerido, esta abordagem não só favorece os alunos, mas tem também beneficiado os museus, apoiando o desenvolvimento de alguns programas e formação e participando na construção de relações de confiança com esta comunidade de prática. Para além disso, este trabalho de fertilização cruzada constitui-se como um dos principais movimentos de fluxo entre a teoria e a prática, desenhando geometrias com fronteiras de contorno híbrido que envolvem, nomeadamente, práticas profissionais, de ensino e investigação. Além disso, este envolvimento da universidade com os seus territóriosde proximidade, numa lógica também de serviço - e ainda que seja sempre necessário manter o espírito crítico e alguma distância epistemológica das práticas ao mesmo tempo que nos envolvemos com estas práticas -, coloca-nos em contacto com diferentes contextos interpretativos, gerando questões de investigação, nomeadamente interativas de ação colaborativa, como já referi. 
Este posicionamento sustenta-se, ainda, nas ideias de Latour e nas abordagens de ciência mais próximas do Modo 2 / 3 de produção de conhecimento científico e tecnológico. Latour, na obra profusamente referida We Have Never Been Modern ${ }^{35}$, argumenta que o nosso mundo é habitado por quase objetos, quase sujeitos. Esses quase objetos são construídos simultaneamente por ambas as partes destas dualidades: são simultaneamente teoria (conceitos) e prática (eventos), sociedade e natureza ${ }^{36}$. A modernidade afirma ser evidente e pura, distinguindo com clareza entre o que é humano e o não-humano, quando, afirma Latour, na realidade está plena de híbridos: quase-humanos, quase-não-humanos sendo este, afinal, o segredo de um dinamismo extraordinário da realidade. A introdução deste conceito permite o encontro entre estes dois mundos de quase objetos, quase sujeitos. Para além disso, a abordagem em termos de Actor Network Theory (ANT), de Latour, alega que a realidade é construída no âmbito de redes de relações nas quais, quer humanos, quer não-humanos, são tratados de igual forma na análise, sendo as relações entre humanos e não-humanos consideradas como partes de redes ${ }^{37}$. As redes de conhecimento são compreendidas como cruzando fronteiras entre o que é objetivo (a natureza), social e os efeitos do discurso, ganhando aqui a co-produção de conhecimento novos contornos. Ao contrário de uma visão tradicional moderna em torno do entendimento do conhecimento enquanto algo que está completamente formado antes da sua disseminação, Latour apresenta-o como sendo produzido no contexto da sua aplicação. O conhecimento é, como se disse já, teorizado como um quase objeto, um híbrido entre sujeito, humano e não-humanos, desafiando, assim, a separação de que aqui falava, entre sujeito e objeto, entre natureza e sociedade, entre teoria e prática.

Neste horizonte de eventos incluem-se também, assim, outros atores e (i)materialidades museológicas: públicos, edifícios, artefactos, profissionais... conhecimento é, pois, compreendido como um híbrido de objetos, artefactos e discursos que estão organizados (ou interrompidos) através de redes de actores, mediadores e intermediários. Os atores envolvidos neste entendimento do que será o horizonte de eventos podem, na verdade, ser quer humanos, quer entidades materiais. Em parte e por essa razão, o nosso conhecimento é impermanente e está em fluxo permanente; não podemos fechá-lo num círculo de representação... mas a vantagem é que permanece aberto ao outro, é que se encontra em processo permanente. De acordo com a visão de Latour, esta abordagem do conhecimento, nomeadamente em museologia, passa a ocupar o espaço entre representações e subjetividade, é impermanente. Impermanência e característica processual que confirma, este, como sendo um espaço de trabalho, formação e investigação que exige abertura ao outro, ao qual as questões éticas não serão alheias e que se apresenta, essencialmente, como espaço de questionamento não delimitador mas de contornos cada vez mais de fronteira no qual - e, de acordo com a preposição de Corynne McSherry -, um objeto de fronteira "tem significados diferentes em diferentes mundos sociais e no entanto está impregnado nicação. Finalmente, o envolvimento com as coleções do museu proporciona o desenvolvimento de competências no manuseamento de objectos e - sem dúvida alguma - uma maior sensibilização do aluno para o pensamento sistémico e criativo, integrando os conhecimentos das outras disciplinas lecionadas no Curso e desenvolvendo projectos verdadeiramente interdisciplinares. A vocação desta disciplina é a de criar um espaço de aprendizagem no qual os alunos são introduzidos ao campo da investigação do estudo e gestão de coleções, fundamentalmente através do estudo de um grupo de objectos / coleção em contexto museológico ou similar. O projecto de avaliação proposto inclui uma reflexão sobre o papel central da investigação de coleções em museus e a discussão e adaptação de diferentes modelos de estudo de cultura material, desenvolvendo / adaptando um modelo ao seu estudo de caso. Este tipo de trabalho implica, necessariamente, um encontro de proximidade não só com as coleções e práticas profissionais mas também com os recursos necessários para o desenvolvimento de competências de investigação nesta área. A interdisciplinaridade com as outras cadeiras lecionadas não só é desejada como é essencial: a avaliação da coleção para a realização de um condition report, por exemplo, faz parte do trabalho a desenvolver numa outra cadeira lecionada no Curso.

35. Cf. Bruno Latour (1993).

36. Idem, p. 51-55.

37. Cf. Bruno Latour, 2005. 
38. Cf. Coryne McSherry (2001, p.69), citada em Marilyn Strathern (2004, p. 45) e Kylie Message (2009).

39. Cf. Helga Nowotny, Peter Scott e Michael Gibbons (2001).

40. Idem; e Helga Nowotny (s.d.).

41. Cf. Helga Nowotny, Peter Scott e Michael Gibbons (2001).

42. Cf. Felix Rauschmayer, Ines Omann e Johannes Frühmann (2009). de significado partilhado suficiente para facilitar a sua tradução entre esses mundos" ${ }^{\prime \prime 3}$.

Fala-se, pois aqui de um objeto quase de investigação / formação que não se enquadrará no Modo 1 de produção de conhecimento. Enquanto no Modo 1 a produção de conhecimento acontece, essencialmente, no contexto das diferentes disciplinas, sendo as questões de investigação / formação definidas e tratadas num contexto regido, em grande parte, pelos interesses de uma comunidade académica específica - que tende a manter as suas premissas fortemente hierárquicas ${ }^{39}$-, as abordagens do Modo 2 de produção de conhecimento são compreendidas como gerando conhecimento mais próximo dos seus contextos e práticas de aplicação. Na verdade, idealmente, esse tipo de conhecimento será verdadeiramente co-produzido com os profissionais-praticantes. O Modo 2 envolve a transdisciplinaridade ${ }^{40}$, a abordagem imediata, eventualmente baseada em problemas e que é avaliada pela sua utilidade em situações práticas. Frequentemente envolve, equipas heterogéneas e transitórias de investigadores que transcendem lugares ou instituições de trabalho particulares, que fazem o seu trabalho de uma forma transparente e socialmente responsável e estão preparados para se submeter a avaliação em termos de controlo de qualidade. Assume contornos de responsabilidade social e de reflexividade. $\bigcirc$ conhecimento é, assim, distribuído socialmente ${ }^{4}$.

Contudo, alguns autores defendem que não se trata apenas de alterar do Modo 1 (investigação essencialmente iniciada pelas universidades e assente em bases disciplinares) para o Modo 2, ou seja, por exemplo, mudar para processos complexos de negociação em curso e de comunicação de uma rede de grupos e indivíduos que se associam para "resolver" um problema mas sim de pensar a ciência e a produção de conhecimento de forma mais sustentável e que tenha em conta a definição de desenvolvimento sustentável apresentada no Relatório Bruntland, que visa a transformação cultural e social. Recentemente os esforços têm-se concentrado, notadamente, na introdução de modelos específicos sobre a qualidade de vida, centrando a discussão nas necessidades, competências, valores, modos de vida, culturas e emoções. Trata-se, defendem Rauschmayer, Omann e Frühmann ${ }^{42}$, de ir mais além, pois se é verdade que a abordagem transdisciplinar está consciente da incerteza e da complexidade das questões (da qualidade híbrida dos quase objeto, diria), também será verdade que necessitamos de uma transformação mais profunda, em direcção a um modo diferente de produção de conhecimento; modo que vem sendo denominado de Modo 3 (termo utilizado pela primeira vez por Friedrich Hinterberger numa apresentação na Conferência de Lisboa da ESEE, European Society of Ecological Economics). A partir das premissas do Modo 2 de produção de conhecimento, esses autores entendem a produção de conhecimento no Modo 3, como sendo capaz de dar sentido às emoções em processos de resolução de problemas, atribuindo autonomia, responsabilidade de interpretação e avaliação das emoções e dos processos internos subjacentes a cada participante envolvido nos processos de resolução de problemas. 
Tendo em conta a natureza social do artefacto museu, perante as reflexões que anteriormente se fizeram deste quase objeto, a inerente abertura ao outro e a caracterização processual que este horizonte de eventos pressupõe, não deveríamos considerar esta abordagem com maior atenção? É verdade que o Modo 2, como nos dizem Frühmann, Omann e Rauschmayer ${ }^{43}$, objectiva abrir a ciência ao público, providenciando interfaces públicas, combatendo problemas reais e procurando soluções que possam ser aceites pelas pessoas afetadas; é verdade que tendo em conta a complexidade dos sistemas e parceiros envolvidos, pretende encontrar as melhores vias de resolução de problemas. No entanto não pretende - pelo menos explicitamente - ampliar a felicidade. Embora este possa não parecer de todo um objetivo que deva ser tido em conta em projetos de investigação / formação volto a pensar no desenho dos círculos - nomeadamente entre o espaço público e o privado -e como são tão pouco definidos por vezes esses contornos. Por outro lado, a questão da felicidade não é de todo alheia às discussões do espaço público cultural e das funções das artes ${ }^{44}$ e fará parte das questões mais amplas que se relacionam com a responsabilidade social.

De resto, as nossas preocupações com as questões ambientais ${ }^{45}$ ou com a responsabilidade social ${ }^{46}$ são bons exemplos de como as questões éticas e esta procura de relevância fora dos contextos habituais se tornou um dos eixos centrais da transformação museológica contemporânea. Estes são sem dúvida alguma alguns dos temas que afetam esta abertura ao outro. Por outro lado, a Actor Network Theory reflete e reproduz este mesmo espaço, construindo - nas abordagens de ciência mais próximas do MODO 2 / 3 de produção de conhecimento - uma ética diferente, tornando-se crítica, responsável perante o outro, ou, enfim, simplesmente ética.

Quereria, ainda, para finalizar esta reflexão e a propósito do conceito de crítica (e sem me alongar mais no desenho destas geometrias), terminar esta reflexão com a questão em aberto que nos deixou também Latour: "Why Has Critique Run Out of Steam? From Matter of Fact to Matters of Concern", onde nos propõe uma versão alternativa, que enfatiza um empirismo realista: uma criticidade que é orientada para detetar o complexo e emaranhado mundo das sociedades com todos os seus peculiares e maravilhosos objetos híbridos. Nesse texto, Latour alega que o crítico não é aquele que desmascara mas aquele que monta; o crítico não é aquele que levanta o tapete debaixo do chão dos pés dos crentes ingénuos mas aquele que oferece as arenas para os participantes se reunirem ${ }^{47}$. Que criticidades estamos, pois, a desenhar? Que espaços-fórum-ágora oferecemos neste nosso espaço público? Que geometrias são estas?
43. Cf. Johannes Frühmann, Ines Omann e Felix Rauschmayer (2009).

44. Ver, por exemplo, Mihaly Csikszentmihaly (2002) e McGonigal (2009).

45. Cf. Sarah Brophy e Elizabeth Wylie (2008).

46. Cf. Robert Janes e Gerald Conaty (2005).

47. Cf. Bruno Latour (2004, p. 246).

\section{REFERÊNCIAS}

BROPHY, Sarah; WYLIE, Elizabeth. Green Museum: A Primer on Environmental Practice. Walnut Creek: Alta Mira, 2008. 
CSIKSZENTMIHALYI, Mihalyi; ROBINSON, Rick. The Art of Seeing: An Interpretation of the Esthetic Encounter. Malibu: J. Paul Getty Museum and Getty Center for Education in the Arts, 1990.

CSIKSZENTMIHALYI, Mihalyi. Flow: The Classic Work on How to Achieve Happiness. Londres: Rider Book, 2002.

DEWEY, John. Democracy and Education. New York: The Free Press, 1916.

DUFF, Wendy; CHERRY, Joan; SHEFFIELD, Rebecka. Creating a Better Understanding of Who We Are': a Survey of Graduates of a Museum Studies Program. Museum Management and Curatorship, Londres, v. 25, n. 4, p. 361-381, 2010.

DUNCAN, Carol. Civilizing Rituals: Inside Public Art Museums. Londres: Routledge, 1995.

FALK, John. Identity and the Museum Visitor Experience. Walnut Creek: Left Coast Press, 2009.

FRÜHMANN, Johannes; OMANN, Ines; RAUSCHMAYER, Felix. Conceptualizing "Mode-3 Science”, Integral Research on Sustainable Development and Quality of Life. 2009. 8th International Conference of the European Society for Ecological Economics / Transformation, Innovation and Adaptation for Sustainability, 2009. Disponível em: <http://www.esee2009. si/papers/Fruehmann-Conceptualizing.pdf>, acessado em 2 de setembro de 2011.

FYFE, Gordon. Sociology and the Social Aspects of Museums. In: MACDONALD, Sharon (ed.). A Companion to Museum Studies. Malden: Wiley-Blackwell, 2006, p.33-49.

GONÇALVES, Maria Eduarda (coord.). O caso de Foz-Côa: um laboratório de análise sociopolítica. Lisboa: Edições 70, 2001.

GREENBERG, Stephen. The Vital Museum. In: MACLEOD, Suzanne. Reshaping Museum Space: Architecture, Design, Exhibitions. New York: Routledge, 2005, p.226-238.

HEIN, Hilde S. The Museum in Transition. A Philosophical Perspective. Washington: Smithsonian Books, 2000.

HOOPER-GREENHILL, Eilean. Museums and the Shaping of Knowledge. Londres: Routledge, 1992.

JANES, Robert R.; CONATY, Gerald T. Looking Reality in the Eye: Museums and Social Responsibility. Calgary: University of Calgary Press, 2005.

JENLINK, Patrick; JENLINK, Karen. Education for Democratic Culture. Cultural Democracy: Taking a Critical Pragmatic Turn. In: JENLINK, Patrick M. (ed.). Dewey's Democracy and Education Revisited: Contemporary Discourses for Democratic Education and Leadership. Lanham: Rowman and Littlefield Education, 2009, p. 229-250.

LATOUR, Bruno. We Have Never Been Modern. Brighton: Harvester Wheatsheaf, 1993.

LATOUR, Bruno. Why Has Critique Run Out of Steam? From Matter of Fact to Matters of Concern. Critical Inquiry, Chicago, v.30, p.225-24, 2004.

LATOUR, Bruno. Reassembling the Social: An Introduction to Actor-Network-Theory. Oxford: Oxford University Press, 2005. 
MACHADO; Fernando Luís; COSTA, António Firmino. Processos de uma modernidade inacabada. Mudanças estruturais e mobilidade social. In: VIEGAS, José Manuel Leite; COSTA, António Firmino (org.). Portugal: Que Modernidade?. Oeiras: Celta, 1998, p.17-43.

MCGONIGAL, Jane. Fiero! Museums as Happiness Pioneers. Museum, Washington, p. 4953, mar.-abr. 2009. Disponível em <http://www.aam-us.org/pubs/mn/museumsandhappiness. cfm>, acessado em 10 de setembro de 2011.

MCGUIGAN, Jim. The Cultural Public Sphere. European Journal of Cultural Studies, Londres; Thousand Oaks, v. 8, n. 4, p. 427-443, nov. 2005.

MCGUIGAN, Jim. The Cultural Public Sphere. In: BENCHIMOL, Alex; MALEY, Willy (ed.). Spheres of Influence - Intellectual and Cultural Publics from Shakespeare to Habermas. Berna: Peter Lang, 2007, p. 243-263.

MCSHERRY, Corynne. Who Owns Academic Work? Battling for Control of Intellectual Property. Cambridge: Harvard University Press, 2001.

MCTAVISH, Lianne. Thinking Through Critical Museum Studies. 2005. Disponível em <http:// atlanticportal.hil.unb.ca:8000/archive/00000024/01/lmctavish.pdf>, acessado em 19 de agosto 2011.

MENDES, Madalena. A globalização e os processos de transnacionalização das políticas educativas. Dialogia, São Paulo, v. 6, p. 106-117, 2007. Disponível em: <http://www.uninove. br/PDFs/Publicacoes/dialogia/dialogia_v6/dialogia_v6_4i39.pdf>, acessado em 19 de setembro de 2011.

MESSAGE, Kylie Museum Studies: Borderwork, Genealogy, Revolution (review article). Museum and Society, Leicester, v.7, n.2, p.125-132, jul. 2009.

MIRZOEFF, Nicholas. An Introduction to Visual Culture. Londres, New York: Routledge, 1999.

NORA, Pierre. Between Memory and History: les Lieux de Mémoire. Representations, Berkeley, v.26, p. 7-24, spr. 1989.

NOWOTNY, Helga. The Potential of Transdisciplinarity. (s.d.). Disponível em <http://helganowotny.eu/downloads/helga_nowotny_b59.pdf>, acessado em 2 de setembro de 2011.

NOWOTNY, Helga; SCOTT, Peter; GIBBONS, Michael. Re-Thinking Science: Knowledge and the Public in an Age of Uncertainty. Cambridge: Polity Press, 2001.

OCTOBRE, Sylvie. Construction et conflits de la légitimité professionnelle: qualification et compétence des conservateurs de musée. Sociologies du Travail, Paris, v. 43, n.1, p.91-109, 2001.

RAUSCHMAYER, Felix; OMANN, Ines; FRÜHMANN , Johannes (ed.). Sustainable Development: Capabilities, Needs, and Well-Being. Londres: Routledge, 2011.

RICE, Danielle. Theory, Practice and Illusion. In: MCCELLAN, Andrew. (ed.). Art and its Publics. Oxford: Blackwell, 2003, p. 77-95.

SEMEDO, Alice. O panorama profissional museológico português. Algumas considerações. Revista da Faculdade de Letras, Ciências e Técnicas do Património, Porto, s.1, v. 2, p. 165-181, 2003. 
SEMEDO, Alice; FERREIRA, Inês. Museus e Museologia: desafios para a construção de territórios colaborativos. Sociologia: Revista da Faculdade de Letras da Universidade do Porto, Porto, s.1, v. 21, p. 97-119, 2011.

SHAFAK, Elif. The Politics of Fiction. TedGlobal 2010, filmado em julho de 2010; posted em julho de 2010. Disponível em <http://www.ted.com/talks/elif_shafak_the_politics_of_fiction. html\#.Tl0PedMS-68.facebook>, gravação MEO 2011, acessado em 19 de agosto de 2011.

SHELTON, Anthony. Negotiating New Visions. An Interview with Anthony Shelton by Gustaaf Houtman. Anthropology Today, Londres, v. 25, n. 6, p. 7-13, dec. 2009.

SIMON, Nina. Beyond Hands On: Web 2.0 and New Models for Engagement. Hand to Hand, Arlington, v. 21, n. 4, winter. 2007. Disponível em <http://www.museumtwo.com/publications/ beyond_hands_on.pdf>, acessado em 29 de julho de 2009.

STOLEROFF, Alan D.; CORREIA, José Alberto; STOER, Stephen R. O novo vocacionalismo na política educativa em Portugal e a reconstrução da lógica da acumulação. Revista Crítica de Ciências Sociais, Coimbra, v.29, p.11-53, fev.1990.

STRATHERN, Marilyn. Working Paper Two: Commons and Borderland. In:

Commons and Borderlands: Working Papers on Interdisciplinarity, Accountability and the Flow of Knowledge. Oxon: Sean Kingston, 2004, p.36-50.

TEATHER, J. Lynne. Museum Studies: Reflecting on Reflective Practice. Museum Management and Curatorship, Londres, v.10, n.4, p. 403-417, 1991.

TEATHER, J. Lynne; VAN MENSCH, Peter; FAULKNER-FAYLE, Sara. Planning for Global Museum Work Shifts. An International Experiment in Career Planning and the Development of a Community of Learners for Museums: the Canadian and the Netherlands Experience. In: ICTOP 1999 Annual Meeting (atas). Londres: ICTOP-ICOM, 1999. Disponível em <http:// www.city.ac.uk/ictop/teather-1999.htm>, acessado em 05 de maio de 2010.

TRODD, Colin. The Discipline of Pleasure; Or, How Art History Looks at the Art Museum. Museum and Society. Leicester, v.1, n.1, p.17-29, mar. 2003.

VAN RIJNSOEVER, Frank J.; HESSELS, K. Laurens. Factors Associated with Disciplinary and Interdisciplinary Research Collaboration. Research Policy, Amsterdam, v. 40, n. 3, p. 463-472, abr. 2011.

ZOLBERG, Vera L. Tensions of mission in American Art Museums. In: DiMAGGIO, Paul J. (ed.). Nonprofit Enterprise in the Arts: Studies in Mission and Constraint. New York: Oxford University Press, 1986, p. 184-198.

Artigo apresentado em 29/10/2012. Aprovado em 16/05/2013 